\title{
Managing Stakeholder Conflicting Expectations in Higher Education: a Hybrid Approach
}

\author{
Abdul Gabbar Al-Sharafi* \& Fatema Al-Rubai'ey \\ Sultan Qaboos University, Sultanate of Oman \\ Received: 5/6/2020 \\ Accepted: $28 / 7 / 2020$
}

\begin{abstract}
This paper proposes a hybrid approach to the management of stakeholder conflicting expectations in higher education (HE) by combining Stakeholder Theory (ST) and a participatory approach. In this paper, we use an ex post facto approach to retrospectively report Sultan Qaboos University (SQU) experience in managing stakeholder conflicting expectations in developing the BA in English Language and Literature Program as a case study. We show that for an effective management of stakeholder conflicting expectations in $\mathrm{HE}$, the three perspectives of ST (i.e., descriptive, instrumental and normative) have to be taken together as a unified approach with the normative perspective occupying the core. In addition, we argue that this unified approach should be complemented by a participatory approach to add an interactive dimension to stakeholder conflict management and allow stakeholders to become active conflict-solvers. The paper concludes that this hybrid approach is essential to manage stakeholder conflicting expectations in academic program development and to project academic program development in HE as a shared social responsibility.
\end{abstract}

Keywords: Higher education, academic program development, conflict management, stakeholder theory, participatory approach

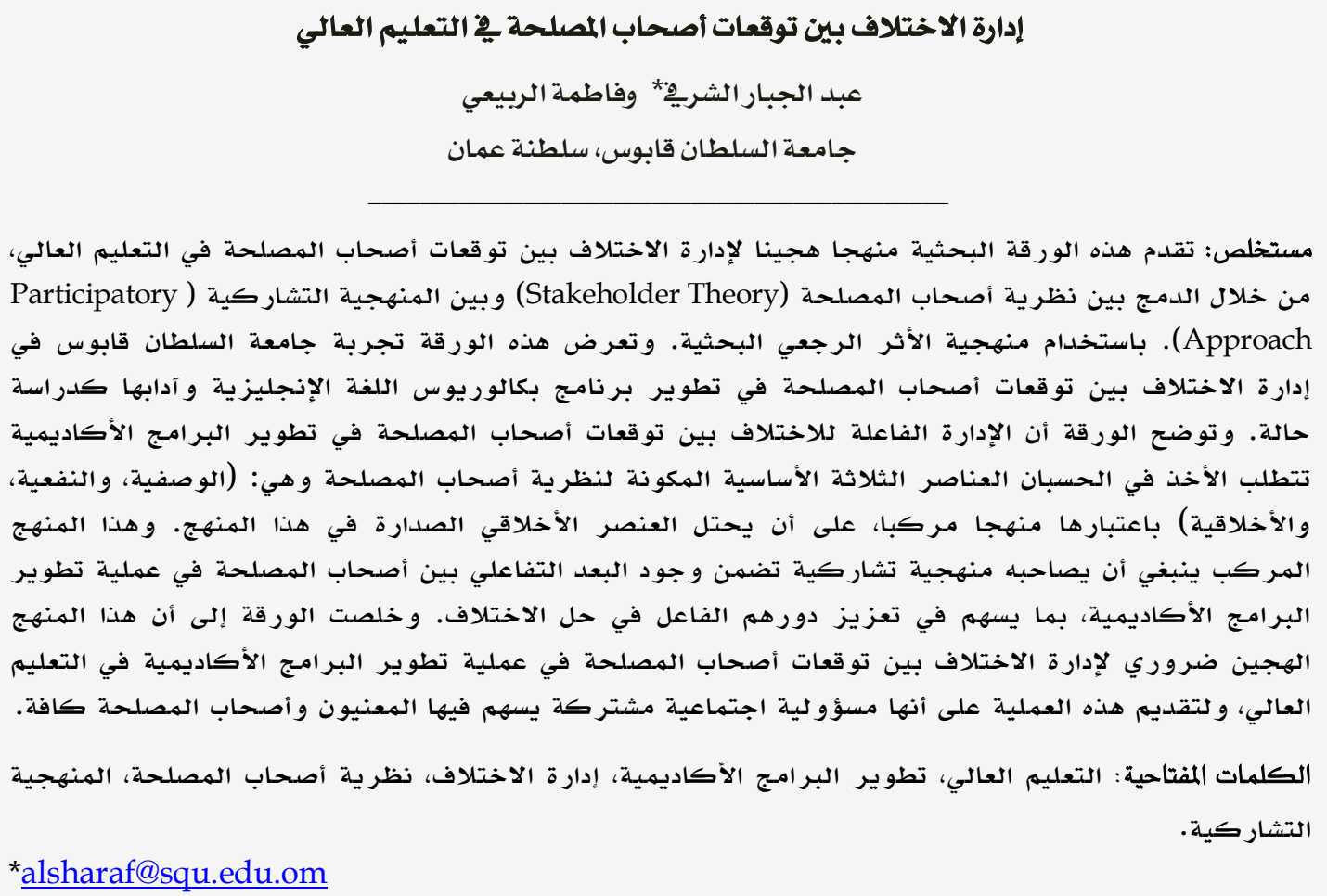


Different stakeholders in HE have different interests, needs and expectations. An issue that has been discussed by a number of researchers (e.g. Dziewanowska, 2017; Cavallone et al., 2020; Merrill et al., 2020). Naturally, "[m]ultiple tensions and conflicts easily arise because of the diverse expectations of the respective groups in the university and the community" (Rubens et al., 2017, p.355). Therefore, conflict is "inherent" in Higher Education Institutions' (HEIs) relationships with their various stakeholders (Strier, 2014). HEIs experienced an increased pressure from different stakeholders to respond to stakeholder diverse needs and expectations and sometimes conflicting claims. However, HEIs cannot respond to the needs and expectations of all stakeholders.

One way to resolve this dilemma is to consider prioritizing relationships with stakeholders by going beyond legitimacy and taking into consideration two important variables: power and urgency (Mitchel et al., 1997). A legitimate stakeholder can be defined as an individual or a group whose actions are desirable and accepted within the constructed system of HEI, while a powerful stakeholder is one who can impose a course of action on the HEI. The urgency attribute, on the other hand, describes the nature of claims made by the stakeholders rather than the stakeholders themselves. Stakeholders' claims can be urgent if they call for the HEI immediate attention (Mitchel et al., 1997; Benneworth \& Jongbloed, 2010). For example, Mitchell et al. argued that a legitimate stakeholder with power is more "salient" to managers than a stakeholder who is legitimate only. However, they asserted that to ensure a "dynamic" relationship with all stakeholders, the legitimacy and power variables should be viewed in light of the degree to which stakeholder claims call for immediate attention, i.e. "urgency." They maintain that a successful relationship with stakeholders should be defined in relation to legitimacy, power and urgency at the same time. The degree of saliency given to each stakeholder would very much depend on how many of these attributes the stakeholder possesses. This approach to stakeholder relationship could be employed to resolve the conflict- ing needs and expectations of stakeholders in HEIs. The weight given to specific needs and expectations of an HEI's stakeholders would be influenced by the degree of saliency of a stakeholder or a group of stakeholders to the HEI.

Even though the prioritization of stakeholder claims is successful in highlighting urgent claims and hence responding to them, it remains purely "instrumental" (Mitchel et al., 1997) or "transactional" (Butcher et al., 2011) in nature, in the sense that it emphasizes a pragmatic objective rather than an ethical value. This approach does not take into consideration the risk of HEIs losing their relationships with some of their stakeholders who believe that their needs are ignored. HEIs cannot afford losing their relationship with their stakeholders (de la Torre et al., 2018), hence, HEIs need to devise a way of prioritizing their stakeholders' relationship while maintaining good relationship with all stakeholders.

One way to resolve this ensuing conflict is to engage all stakeholders in a dialogue to negotiate differences, reach a consensus and create a shared vision about the claims and expectations of all stakeholders using the "participatory approach" (Guijt \& Gaventa, 1998; Guijt, 2014). Guijt (2014) maintains that participatory approach is used in impact evaluation to obtain stakeholders' opinion on issues relevant to them. It can be used in any stage of the impact evaluation including evaluation design, data collection, data analysis and in the discussion of findings, forwarding recommendations, and reporting.

Guijt (2014) notes that there are two rationales for choosing the participatory approach for involving stakeholders: pragmatic and ethical or a combination of both. It is pragmatic because "better evaluations are achieved (i.e., better data, better understanding of the data, more appropriate recommendations, better uptake of findings); ethical because it is the right thing to do (i.e., people have a right to be involved in informing decisions that will directly or indirectly affect them" (Guijt, 2014, p.2).

Each HEI has its own mission which is influenced by the socio-economic and cultural variables of the local context. There- 
fore, the type of stakeholders most relevant to each HEI and its mission will vary considerably from one context to another and from one institution to another. Therefore, one of the key factors for successful management of stakeholder expectations in general and conflicting claims in particular is to develop a stakeholder management system which is situated in the local context of the HEI (Jongbloed et al., 2008; Marsall, 2018). This study illustrates how the management of stakeholder conflicting expectations evolved in its organic context and the "functional and structural addons" (Jongbloed et al., 2008) that SQU adopted to address this characteristically localized experience.

In this article, we address the question of what can be learned about the management of stakeholder conflicting expectations in HE using the BA program in English Language and Literature at SQU as a case study. First, we introduce the Stakeholder Theory (ST) and its three main perspectives: descriptive, instrumental and normative. Second, we trace the introduction of ST in the field of HE. Third, we report the activities of the case study. Finally, in the discussion, we retrospectively reflect on this case study by contextualizing it within the literature of stakeholder management in higher education and discuss the implications.

\section{Stakeholder Theory}

The Stakeholder Theory (ST) was developed by Freeman (1984) within the business management field. Freeman defines the notion of stakeholder as "any group or individual who can affect or is affected by the achievement of the organization's objectives" (p. 46). Investment in stakeholder relationships can be realized in three different ways: accurately describing stakeholders and their roles (the descriptive perspective), characterizing the instrumental impact of stakeholders in achieving the organization's objectives (the instrumental perspective), and prescribing the moral dimension of stakeholders' involvement (the normative perspective) (Donaldson \& Preston, 1995).

There are different classifications of stakeholders. From a descriptive point of view, stakeholders are classified into primary and secondary (Marić, 2013), overt and latent (Jongbloed et al., 2008; Garvare \& Johansson, 2010; Mainardes et al., 2013), commercial and noncommercial (Melewar \& Akel, 2005), and internal and external (Marshall, 2018). From an instrumental perspective, stakeholders are classified into latent stakeholder, expectant stakeholder, and definitive stakeholder based on the stakeholder's possession of one or more of stakeholder relationship attributes: power, legitimacy, and urgency (Mitchell et al., 1997). Legitimacy is defined as "a generalized perception of assumption that the actions of an entity are desirable, proper, or appropriate within some socially constructed system of norms, values, beliefs, and definitions" (Suchman, 1995, p.574). Power is defined as "a relationship among social actors in which one social actor, A, can get another social actor, B, to do something that B would not have otherwise done" (Pfeffer, 1981, p.3). Urgency is defined as "the degree to which stakeholder claims call for immediate attention" (Mitchell et al., 1997, p.869).

The possession of one or more of these attributes defines the degree of saliency of a stakeholder to the organization managers. The saliency of a stakeholder is defined as the "the degree to which managers give priority to competing stakeholder claims" (Mitchell et al., 1997, p.869). As different stakeholders normally have different claims or contributions for the institution, managers need to prioritize the attention they give to different stakeholders by taking into consideration not only legitimacy and power of a stakeholder but also urgency. Legitimacy and power can be perceived as independent qualities to facilitate the identification and characterization of stakeholders. However, urgency is the attribute that adds a dynamic dimension to the manger-stakeholder relationship.

While the descriptive perspective defines "the states of affairs of corporations and their stakeholders," the instrumental one evaluates the impact of stakeholders on achieving the corporations objectives or 
"profitability" (Donaldson \& Preston, 1995, p.71). On the other hand, the normative perspective explains the moral guidelines for involving stakeholders. It is about the stakeholders' right to voice their claims and for their claims to be addressed by the corporation even when such claims have no instrumental value to the corporation.

Donaldson \& Preston (1995, p.74) argue that these three perspectives make "the three aspects of stakeholder theory" which "are nested within each other" with the normative aspect as "the central core." This view is in line with Evan and Freeman's (1988, p.103) argument that the purpose of the firm is "to serve as a vehicle for coordinating stakeholder interests" rather than focusing on the firm's best interest.

\section{Stakeholders in higher education}

Higher Education (HE) has gone through two major shifts, namely first and second academic revolutions, affecting its functions (Rubens et al., 2017). The first academic revolution which took place in 1810, brought "research" as the second mission of the university in addition to the first or "primary mission" which is "teaching" (Trencher et al., 2014; Rubens et al., 2017). These two missions neither mandated the engagement of the university with its surrounding community nor allowed the interference of the community in the university.

The second academic revolution which started in 1980s mandated "community engagement" as a third mission of the university. This shift was motivated by major socio-economic changes worldwide. Economic recession of the time forced governments to austerity measures including cutbacks in HE funding. This required higher education institutions (HEIs) to reach out to the surrounding community for funding. In return, companies and corporates realized the importance of forging partnerships with HEIs to help them cope with the financial difficulties and "increase the competitiveness of national economies" (Rubens et al., 2017, p.356).

However, community engagement as the third mission of the university does not only mean commitment to educational, social and economic services but also a definition of the university's "relationship with the non-academic outside world: industry, public authority and society" (Schoen et al., 2007, p.127), or as Boyer $(1990,1996)$ describes it, HEIs are on a mission to serve the community and actively interact with it.

Part of defining HEIs' relationships with stakeholders is to identify, classify and prioritize these relationships. The most common classification of stakeholders in HE literature is the descriptive classification of internal -external stakeholders (Melewar \& Akel, 2005; Labanauskis \& Ginevicius, 2017; Marshall, 2018). Internal is mainly reserved for faculty members, university academic and administrative staff and sometimes students. Students are sometimes viewed as internal stakeholders since they belong to the university context. However, some researchers view them as external stakeholders because they are viewed as "end users" or receivers of the university services and hence affected by the practices of the internal stakeholders of the university (de la Torre et al., 2018). External stakeholders include representatives from the social and industry sectors and policy makers including employers from different public and private sectors, alumni, and legislators.

While these general categories of external HEIs' stakeholders are somehow fixed, the representative sample of external stakeholders could be expanded to include anyone who can affect or is affected by the services of HEIs (Freeman, 1984), which could very much vary from one context to another. When the expertise of local and international experts is sought by HEIs on some issues, they could be treated as legitimate stakeholders albeit "temporary stakeholder" since they could only influence the HEIs" on issues they are consulted on and for a named/specific period.

\section{Context of the case study}

HE in the Sultanate of Oman is fairly recent. It started in 1986 by the establishment of SQU, the only public and leading university in the Sultanate. Academic program development at SQU can be approached in two different ways: new pro- 
gram (a program developed from scratch) and review-dependent program (i.e., a new program developed based on the recommendations of an academic review conducted on an existing program).

As an autonomous HE institution, SQU was given the privilege of developing academic programs without necessarily consulting all stakeholders. Stakeholders are classified into internal (faculty, policy makers and students) and external (employers, advisory board members, and international academic experts/reviewers).

Stakeholder participation in the development of the BA in English Language and Literature has gone through three main stages: no participation, deferred participation, and limited participation. These stages of stakeholder involvement, however, are reserved to categories of stakeholders other than faculty and policy makers because these latter categories are permanent and stable stakeholders whose participation is taken as a given.

In 1987, the BA in English Language and Literature was developed to reflect two perspectives. The first one was that a BA in English Language and Literature was seen as a key component of an academic HEIs following the then predominant university models. The second one is the practical perspective which concerned the local needs for graduates with good English language skills to serve in various government institutions. The task of developing this program was assigned to a group of academics who put together the study plan and developed the courses for this program without a program vision, mission, learning outcomes and without consulting other stakeholders.

In 2007, the Department faculty members were required to develop a program profile describing the program vision, mission, objectives and learning outcomes in response to quality assurance regulations mandated by Oman Accreditation Council which was established in 2001 and renamed in 2010 as Oman Academic Accreditation Authority, OAAA. However, this program profiling remained solely in the hands of academics and there was no stakeholders' participation. These efforts, therefore, characterize the no participation stage of stakeholder involvement in academic program development at SQU.

In 2015, the BA in English Language and Literature was one of the first programs that went through academic program review at SQU. When the Self Study Report (SSR) was developed, feedback from a small sample of students and alumni was collected using surveys. Other categories of stakeholders such as employers were not consulted. During the site visit, the panel of international reviewers interviewed faculty members and key figures at SQU. They also met with some of the Department Advisory Board members, students, and alumni. A major recommendation of the review panel was to develop a new BA program. The implementation of this recommendation was left in the hands of the Department faculty who were expected to develop an implementation action plan and act upon it without consulting other stakeholders. Therefore, the involvement of stakeholders in the new program development was still limited. This effort represents the limited participation stage, because even though various categories of stakeholders are involved, their involvement is limited in scope and quantity.

The reviewers' recommendation to develop a new BA program initiated a new BA program development process. However, the process was left in the hands of the Department faculty who were expected to develop a proposal for a new BA program, and consult international experts and employers only when the proposal is completed, which characterizes the deferred participation stage. In this case study, however, this stage was suspended due to conflict among stakeholders about the future direction of this program.

This conflict was related to the amount of change and the future direction of the program. Most importantly, the issue of how much of labor market expectations can the program accommodate. To resolve this conflict, the authors in their role as department administrators decided to embark on a wide scale data collection 
exercise. Data were collected from internal stakeholders (i.e., faculty, students, policy makers, and academic experts) and external stakeholders (i.e., alumni and employers including advisory board members).

\section{Methodology}

Using an ex post facto research approach, we retrospectively report the activities that took place in the case study of developing the BA program in English Language and Literature, and reflectively interpret these activities in light of the ST framework and the participatory approach (see the discussion section). The ex post facto approach is defined as the type of research in which "the researcher takes the effect (or dependent variable) and examines the data retrospectively to establish causes, relationships, or associations and their meanings" (Cohen et al., 2018, p.418).

The authors were involved as participants and observers in the case study. They were also involved as key players in their capacity as head and deputy head of the department in which the case study took place. These roles provided the authors with access to all program relevant information and documentation and made them involved in all the phases of this program development. In addition, these roles enabled the authors to coordinate with all categories of stakeholders, gave them the privilege to see the conflict in stakeholder expectations emerge and required them to manage this conflict in consultation with SQU policy makers and other stakeholders.

\section{BA program background information}

The English Language and Literature program is a four-year undergraduate program which was established in 1987. There are no official records of the mission, vision and educational program objective at its inception. They were developed in 2007 as a response to the quality assurance requirements of OAAA (see above). Therefore, the courses were designed without any such guiding principles. The annual intake of the program is 120 students as of 2015.

\section{Participants}

The data in this case study was collected in the period from May 2017 to December 2018. Table 1 below summarizes the information about the participants in this data collection exercise. The authors are classified as internal stakeholders because they are faculty members.

\section{Data collection tools and procedures}

Two types of data were collected in this project: archival and elicited data (Bernard \& Ryan, 2010). The archival data covered data that were deemed necessary for situating the current project of developing a new BA program in the local context, such as: Oman Vision 2040, SQU Strategic Plan 2016-2040, and the report of the National Project for the Alignment of Higher Education Graduates with the Needs of the Omani Labor Market. In addition, an environment scanning exercise was conducted to situate this future BA program in the EFL international context in terms of current trends of similar program name, focus, structure and curriculum. 
Table 1

Stakeholders' information

\begin{tabular}{llcl}
\hline $\begin{array}{l}\text { Classification of } \\
\text { Stakeholders }\end{array}$ & Participants & $\begin{array}{l}\text { Number of } \\
\text { Participants }\end{array}$ & Background \\
\hline $\begin{array}{l}\text { Internal } \\
\text { (from SQU) }\end{array}$ & Students & 122 & - English Language and Literature Program \\
& $\begin{array}{l}\text { Faculty } \\
\text { Policy makers }\end{array}$ & 18 & $\begin{array}{l}\text { - Department of English Language and Literature } \\
\text { - SQU Administration }\end{array}$ \\
& Academic experts & 6 & $\begin{array}{l}\text { - Deanship of Admissions and Registration } \\
\text { - Business Communication Unit-College of Eco- } \\
\text { nomics and Political Science }\end{array}$ \\
& & & $\begin{array}{l}\text { - English Education Program-College of Education } \\
\text { - English Language and Literature Program }\end{array}$ \\
$\begin{array}{l}\text { External } \\
\text { (from outside } \\
\text { SQU) }\end{array}$ & Alumni & 65 & $\begin{array}{l}\text { Employers from private and public sectors in- } \\
\text { cluding advisory board members }\end{array}$ \\
\hline
\end{tabular}

Elicited data were collected using three data collection tools, namely, questionnaires, focus groups and semi-structured interviews. The questionnaire allowed for collecting data from larger sample of participants, the semi-structured interview and the focus group allowed for deeper understanding of the participants views. In the case of small samples of participants, either interviews or focus groups were used only. For example, interviews were seen suitable with six SQU policy makers. In addition, due to their busy schedule, it was difficult to collect data from them using the focus group method. On the other hand, it was feasible to conduct the focus group with SQU academic experts. Due to the contested views on the nature and scope of changes in the BA program among faculty members, the survey was seen more appropriate to collect data from them. The survey allowed the faculty members to express their personal views without peer pressure.

The remaining categories (i.e., current students, alumni and employers) represented the largest number of participants in this project. Therefore, a combination of questionnaires and focus groups were used to collect data from them. Data were collected concurrently from all participants. In their role as faculty members, the authors responded to the faculty questionnaire. In their administrative role, they participated in designing the data collection tools, in administering them and in supervising the whole process of data collection.

All types of data collections were constructed by a group of faculty members and validated by two other faculty mem- bers in addition to two Department Advisory Board members from the industry.

\section{Data analysis procedures}

The authors conducted a thematic analysis on the elicited data and the archival data (Bernard \& Ryan, 2010). Data relevant to academic program development were extracted from the archival data documents and placed under themes that carry the name of the original archival document. Since the questions in the data collection tools were designed to target a set of themes relevant to academic program structure, these themes were used to guide the thematic analysis. However, other themes were allowed to emerge from the data. The summary of the analysis was compiled in one report (i.e., data report).

\section{Results}

The data analysis revealed that there was a disagreement among stakeholders with regard to scope and nature of change in program focus, program structure, program name, and curriculum. For example, the data revealed that there were three different patterns of stakeholders' attitude towards the change in the program focus: change-resistant, change-conservative, and change-advocate. Majority of faculty members were change-resistant because they did not see value in changing the current program (Example 1). They argued that the current program should be revised by adopting minor changes in the curriculum while maintaining the same focus.

\section{Example 1:}

Faculty: "Literature can teach students the skills which can be adapted 
to different sectors. However, we need to demonstrate the adaptability of literature to workplace, to students, and employers."

The employers and majority students and alumni, however, as change-advocates contended that a totally new BA program should be developed with new focus, name, structure and curriculum (see Example 2, 3, and 4). As for the nature of these changes, they recommended that such changes be aligned with the needs of the Omani labor market which represent the current changes and future directions of the economy and hence shape the current and future directions of employment.

\section{Example 2:}

Employer: "Studying English Literature is a luxury... a BA degree in English Literature which was not developed to respond to a real need in the Omani labor market is, therefore, no longer appealing to the Omani market dynamics.

Example 3:

Student: "It is not clear to us how the knowledge of the English Literature is relevant to the job market."

\section{Example 4:}

Alumni: "employers are put off by the word 'literature' in the title of the degree. They don't trust us because of this word. Sometimes they don't know where to place us."

On the other hand, SQU policy makers and academic experts cautioned against making changes solely based on the market needs because such needs are volatile and hence cannot be accurately predicted. However, they affirmed that any changes in the program should be data-driven and the external stakeholders should be consulted (see Example 5 and 6). SQU policy makers and academic experts could be described as change-conservatives.

\section{Example 5:}

Policy "We don't want to be maker: driven by the market needs alone because the market needs are volatile. Any changes in the program should be datadriven."

\section{Example 6:}

Academic "We have to continue to expert: take into consideration the demands of the job market and strike a balance between expectations and reality...However, the program should have a unique academic identity."

As can be seen, the data were not conclusive since they did not provide a clear direction on the future of this program. Two issues should be noted here. First, this discrepancy in stakeholders' views could be attributed to the fact that the data were collected from each type of stakeholders in isolation of others. Second, the most change-resistant category of stakeholders is the faculty members. Even though they represent a small number of participants in the data collection phase, they are the most powerful category of stakeholders. SQU system gives them the right to develop, approve and implement a new academic program. The approval process of a new academic program proposal is initiated by department board approval via majority vote of faculty without which the approval process is halted.

The authors consulted SQU administration on how this disagreement could be resolved. Being aware of the power SQU regulations give to faculty members and the validity of the claims made by other stakeholders (employers and majority alumni and students) about changing the program in line with the expectations of Oman Vision 2040 and Omani labor market expectations, SQU administration suggested holding a national workshop. Representative samples from all types of stakeholders were invited in one place to engage in a constructive discussion about the findings of the study and to reach a consensus about the future direction of the program. All national workshop partici- 
pants were given copies of the data report prior to the event to allow focused discussion in the workshop.

\section{The national workshop}

A total of 102 participants representing Department students, Department alumni, Department faculty, employers and academic experts from different institutions in Oman were invited to participate in a national workshop to discuss the findings of the study and recommend a direction for the future of this BA program. Due to the nature of their administrative roles, SQU policy makers were not invited to participate in the workshop so they do not influence the discussion. In addition, the authors did not contribute to the workshop discussion. Their role was limited to preparing workshop materials including developing a detailed guideline for the moderators and note-takers, a guideline for roundtable discussion, and an infographic report based on the data report. In addition, they were responsible about recruiting stakeholder participants from all categories. On the day of the workshop, their roles were limited to moderation and observing the discussion.

The workshop consisted of an opening in which an international guest speaker delivered a plenary speech about how literature programs have been reinventing themselves to meet labor market demands. The opening was followed by the first roundtable session, a crossfertilization session, a floor discussion and a final stakeholder representative roundtable. In the first roundtable session, the participants sat in the tables designated for their relevant stakeholder categories. Each roundtable consisted of a maximum of 8 participants, a moderator and a note taker. All participants were provided with general guidelines for discussion procedures, a copy of the data report and infographic report. The infographic report aimed to provide a brief diagrammatic representation of the main trends in the data. The report functioned as a quick reference to ease the discussion in the workshop by helping the participants to access the data and patterns of data quickly and easily. In this session, the participants dis- cussed the findings of the study and narrowed down their recommendations to one or two recommendations maximum for each theme. This session lasted for one hour and a half and was followed by half an hour cross-fertilization session in which the moderators and note takers exchanged positions within the same category of stakeholders. For example, the moderator and note taker in Employer table (1) moved to Employer table (2) to brief them about the recommendations reached in table (1) and vice versa. After that, one representative from each table was invited to the stage to answer questions from the participants of other tables pertaining to the focused recommendations reached at their table.

After the floor discussion, a final one-hour round table session took place. In this session, representatives of all stakeholder categories reviewed the focused recommendations reached by all categories and narrowed them down in light of the feedback received in the floor discussion. After the workshop, the guest speaker submitted a report about his recommendations for the future directions of the program based on his observation in the workshop.

The discussion in the national workshop was systematic, well-structured and goaloriented which made it easy for the participants to reach a shared vision and a consensus regarding the following themes: program focus, program name, program options, and program curriculum. Including a representative sample of all stakeholders in the decision-making process proved to be essential and the recommendations reached in this workshop were focused, insightful and informative. The stakeholder representatives and the international guest speaker recommended developing a new BA program with the following in mind (see Table 2). 
Table 2

Recommendations of the National Workshop and guest speaker

\begin{tabular}{|c|c|}
\hline Theme & Stakeholder Representatives Recommendations \\
\hline Program Focus & $\begin{array}{l}\text { 1. New areas of specializations that cater for the market needs in the areas of language } \\
\text { linguistics, communication and literature } \\
\text { 2. Literature should focus on modern literature and world literature. }\end{array}$ \\
\hline Program Options & One core program with specializations \\
\hline Program Name & $\begin{array}{l}\text { 1. English Studies (With the specialization following) } \\
\text { 2. English Language Studies (with specialization following) } \\
\text { 3. English (with specialization following) }\end{array}$ \\
\hline Curriculum & $\begin{array}{l}\text { 1. Theory and application should be integrated in all courses. } \\
\text { 2. Literature should be taught as discourse and should explicitly serve the development } \\
\text { of other required skills. } \\
\text { 3. Experiential learning should be incorporated in the program. } \\
\text { 4. Professional English oral and written communication skills are required. }\end{array}$ \\
\hline
\end{tabular}

\section{Discussion}

In order to understand how SQU managed its stakeholder conflicting expectations in the academic program development of the BA program in English Language and Literature, we need to reflect, first, on how SQU classified its stakeholders in the process of developing this BA program from ST descriptive, instrumental and normative perspectives.

\section{Descriptive perspective}

From a descriptive point of view, stakeholders in both cases of program development (i.e., new program development and review-dependent program development) are classified into "internal" and "external" (Marshall, 2018). Internal stakeholders include faculty members, students, and SQU policy makers. External stakeholders include employers represented in the advisory board (henceforth advisory board), employers not represented in the department advisory board (henceforth employers), alumni, and "temporary stakeholders" in the form of international academic experts in the case of new program or international academic reviewers in the case of academic review (Table 3).

Even though the BA program development under examination is reviewdependent, the development phase was

suspended due to the conflict among stakeholders regarding the future of this program. Therefore, the post-review data collection exercise was launched to elicit views on the future directions of the program. When the data revealed that a con- flict among stakeholders on the nature and scope of changes for the new program still persisted, another round of stakeholders' involvement was initiated in the form of a national workshop.

\section{Instrumental perspective}

From an instrumental perspective, internal and external stakeholders involved in both types of program development (i.e. new program development and reviewdependent program development) can be considered "legitimate" stakeholders. Their participation is mandated by SQU academic program review and program development policies. As for the "power" attribute, the highest degree of power in program development is given to faculty members and policy makers. This is gleaned from, first, the classification of faculty and policy makers as stable internal stakeholders. Second, SQU system gives both types of stakeholders the right to approve a new academic program. However, there is a difference in the power structure of these two categories. Faculty members exercise more power than policy makers do at the initial stage of the new academic program approval process, while policy makers exercise more power at the subsequent stages of the approval process. The approval of faculty members of a new program proposal via majority vote is a critical step without which the approval process will be halted. Once the proposal is approved by faculty members, SQU system gives policy makers full power to accept or reject the proposal. Therefore, faculty members act as gatekeepers of the approval process, while policy makers act as exit-guards of this process. 
Table 3

Classification of stakeholders in the development of the BA in English Language and Literature at SQU

\begin{tabular}{|c|c|c|c|}
\hline $\begin{array}{l}\text { Phases of Review- dependent } \\
\text { Program Development }\end{array}$ & Internal stakeholders & External stakeholders & $\begin{array}{l}\text { Type of partic- } \\
\text { ipation }\end{array}$ \\
\hline & 1. Faculty & 1. Advisory board & Limited \\
\hline \multirow{2}{*}{ 1. Review Phase } & 2. SQU Policy makers & 2. Alumni & \\
\hline & 3. Students & 3. International academic reviewers & \multirow{3}{*}{$\begin{array}{l}\text { No Participa- } \\
\text { tion }\end{array}$} \\
\hline \multirow{2}{*}{$\begin{array}{l}\text { 2. Development Phase } \\
\text { (suspended due to conflict) }\end{array}$} & 1. Faculty & 3. Employers & \\
\hline & 2. SQU policy makers & 4. International academic experts & \\
\hline \multirow[t]{4}{*}{ 2.1. Post-Review Data Collection } & 1. Faculty & 1. Advisory board & \multirow[t]{4}{*}{ Inclusive } \\
\hline & 2. SQU policy makers & 2. Employers & \\
\hline & 3. Students & & \\
\hline & $\begin{array}{l}\text { 4. Local academic ex- } \\
\text { perts (from SQU) }\end{array}$ & & \\
\hline \multirow{2}{*}{$\begin{array}{l}\text { 2.2. Development Phase } \\
\text { (suspended due to conflict) }\end{array}$} & 1. Faculty & 1. Employers & \multirow{2}{*}{$\begin{array}{l}\text { No Participa- } \\
\text { tion }\end{array}$} \\
\hline & 2. SQU Policy makers & 2. International academic experts & \\
\hline \multirow[t]{5}{*}{ 2.3. National Workshop } & 1. Faculty & 1. Alumni & \multirow{5}{*}{ Inclusive } \\
\hline & 2. Students & 2. Advisory board & \\
\hline & 3. Local academic & 3. Employers & \\
\hline & experts (from SQU) & $\begin{array}{l}\text { 4. International academic } \\
\text { specialist }\end{array}$ & \\
\hline & & $\begin{array}{l}\text { 5. Local academic experts } \\
\text { (from outside SQU) }\end{array}$ & \\
\hline \multirow{2}{*}{$\begin{array}{l}\text { 2.4. Development Phase } \\
\text { (In Progress) }\end{array}$} & 1. Faculty & 1. Employers & \multirow[t]{2}{*}{ Deferred } \\
\hline & 2. SQU Policy makers & 2. International academic experts & \\
\hline
\end{tabular}

As for "urgency," all stakeholders made claims about the nature and scope of change in the new program; however, not equally "urgent" in the sense of "call[ing] for immediate attention" (Mitchell et al., 1997, p.869). Majority faculty members, for example, argued for maintaining the same focus of the existing program with minimum changes in its curriculum. On the other hand, some faculty members in addition to majority students, alumni, and employers called for a totally new program aligned with the needs of the Omani labor market. They claim that the country is going through major socio-economic changes that radically shifted the dynamics of employability landscape in Oman. To them, a BA degree in English Language and Literature is no longer appealing to the Omani labor market. Hence, in their view, this academic program should be totally changed in response to the urgent needs of the Omani labor market. In fact, the archival data collected confirm the urgency of their claims. These claims are supported by Oman Vision 2040 with which all institutions in the country are required to align their strategic plans and practices to respond to the socio-economic changes and enhance employability of Omani graduates, including SQU whose strategic plan 2016-2040 emphasizes this orientation.

SQU administration was aware of this conflict situation. They did not find it easy to prioritize one stakeholder category over the others given the power that one category has vis-a-vis the urgent claims of other categories because SQU administration recognizes its moral commitment towards achieving the best interest of all stakeholders and the local context. Therefore, all categories of stakeholder were deemed equally "salient." Thus, the instrumental approach alone was insufficient to address stakeholder conflicting expectations in the development of this BA program. To resolve this conflict there was a need to complement the descriptive and instrumental perspectives with the normative one.

\section{Normative perspective}

From a normative perspective, SQU administration is morally committed towards maintaining equal relationship with all categories of stakeholders and towards its role as a leading HEI in the country. SQU recognizes its moral obligation to giving equal attention to claims and expectations of all stakeholders. Therefore, SQU opted for a participatory approach 
using open dialogue in which all categories of stakeholders were invited to participate in a constructive discussion to reach a shared vision for a new BA program aligned with the needs of the Omani labor market. This participatory approach enabled SQU to achieve its instrumental objective which is reaching a consensus about the future direction of the new BA program. It, also, enabled SQU to achieve its normative objective which is fostering a culture of collaborative involvement in which all stakeholders are equally engaged, their expectations are treated as equally important and the prioritization of their expectations is goal-driven and target-oriented. This culture enabled SQU to respond to the socio-economic changes in the country and resolve its stakeholders' conflicting expectations. The authentic activities of this case study support the argument that the normative perspective should be the "core" of any stakeholder management initiative (Donaldson \& Preston, 1995; Mitchell et al., 1997).

\section{Recommendations}

\section{Stakeholder management in higher edu- cation}

In the field of business where ST originally started, the focus is usually on the instrumental perspective because the aim is often to generate profit. However, when applying ST in the field of HE and particularly in the area of academic program development, it is not possible to give priority to the instrumental perspective over the descriptive and normative perspectives. In this case study, it was difficult to manage stakeholders' relationships using purely descriptive or instrumental perspectives. It was only when the normative perspective was integrated that SQU was able to effectively manage its stakeholders' relationship achieving its instrumental and normative goals. Therefore, the three perspectives need to complement each other in order to achieve a balanced way of managing stakeholders in HE. This view is in line with Donaldson and Preston (1995, p.74) that these three perspectives of ST are "nested within each other."

In fact, this case study reveals that the normative perspective should be given more weight in the management of stakeholders in HE considering the fact that HEIs have a social, cultural and economic responsibility to and impact on society. Therefore, HEIs are morally obliged to society in two different ways. First, they are morally responsible to graduate human capital who fulfill socio-economic expectations. Second, they are morally committed to engage the society (i.e. all stakeholders) in academic program development. This view agrees with Donaldson and Preston's call that the normative perspective should be the "central core" of ST (1995, p.74), and in our view in particular in the field of HE and more precisely in academic program development.

In this case study, the participatory approach was used simultaneously to achieve instrumental and normative objectives, which reiterates Guijt's (2014) argument that the participatory approach is used for pragmatic and/or ethical reasons. In our view, this is the most inclusive and interactive approach to stakeholder involvement in academic program development. It allowed stakeholders to actively participate in resolving the conflict in their expectations.

The activities adopted by SQU to mange its stakeholder conflicting expectations in academic program development resulted in combining ST theory with the Participatory Approach. This hybrid approach is fully responsive to contextual demands be it that of the institution or the local context. The hybrid approach echoes consistent calls to localize stakeholder management practices in HE (Jongbloed et al., 2008; Beneworth \& Jongbloed, 2014). From this case study, we can learn that theoretical models of stakeholder management can be of benefit for HEIs, but HEIs need to adapt these models to their needs and to their local context even if this adaptation could lead to "functional and structural add-ons" (Jongbloed et al., 2008) to established models of stakeholder management in HE.

\section{Stakeholder management at SQU}

This is the first research project to address the issue of how SQU managed its stakeholder conflicting expectations in academ- 
ic program development. SQU should conduct further research in this important area to cover the identification, classification and prioritization of its stakeholders. This will help SQU build its own localized system of stakeholder management.

The experience of developing the BA program in English Language and Literature is unique because it is the first of its kind at SQU in the sense that it involved this magnitude of stakeholders and triggered a national dialogue about the development of an academic program in Oman. In a proper academic program development, all stakeholders should be involved in all stages of program development, particularly the stage where those key decisions regarding program vision, mission, objectives and curriculum are taken. Using the "inclusive approach" in academic program development recognizes the role of all stakeholders in the decision-making process of academic program development. Therefore, SQU should formally adopt a participatory approach for stakeholder involvement in its academic program development practices. This approach gives a triangulated 360-degree view of all stakeholders' perspectives and makes academic program development a shared social responsibility.

Even though SQU successfully managed its stakeholders in this experience, the case study revealed that SQU does not have an established system of stakeholder management. This explains the lack of stakeholder management policies. To effectively manage its stakeholders, SQU needs to issue policies that accurately describe its stakeholders and their roles, characterize their instrumental impact on achieving SQU objectives, and prescribe the moral dimension of stakeholders' involvement in academic program development (Donaldson \& Preston, 1995).

Both the system and the policies should create a culture that fosters stakeholder involvement and engagement in various administrative and academic activities of SQU, the chief of which is academic program development activities. This culture is vital as it reflects the conviction that, while academic programs are owned by
HEIs, they, indeed, affect the whole society over generations, hence their impact on society.

\section{Conclusion}

This paper reports an authentic experience of stakeholder management in HE which evolved within its ecology with no apriori theoretical frame resulting in the creation of a hybrid approach that is locally inspired but retrospectively contextualized in the literature of stakeholder management. The implementation of a three dimensional approach of descriptive, instrumental and normative perspective of stakeholders' management in HE with the normative perspective at the center of this approach coupled with a participatory approach projected academic program development as part of an ecosystem in which HEIs are affecting and affected by socioeconomic changes and developments. HEIs can no longer afford to operate in insolation of their stakeholders, because the notion of HEI as an isolated "republic of scholars" is no longer compatible with current socioeconomic changes. It created an understanding that HEIs cannot be limited to the first and second missions, namely teaching and research. In addition, the implementation of this hybrid approach created a cultural awareness among different categories of stakeholders about their perception of their roles and those of others in academic program development. HEIs should fully embrace the third mission which is community service in the wider sense which includes community engagement using the three dimensional approach of stakeholder engagement and the participatory approach.

\section{References}

Benneworth, P., \& Jongbloed, B. (2010). Who matters to universities? A stakeholder perspective on humanities, arts and social sciences valorisation. Higher Education, 59, 567-588. doi: 10.1007/s10734-009-9265-2

Bernard, H. R., \& Ryan, G. W. (2010). Analyzing qualitative data: systematic approaches.CA: Sage Publications 
Boyer, E. L. (1990). Scholarship reconsidered: Priorities of the professorate. NJ: The Carnegie Foundation for Advancement of Teaching.

Boyer, E. L. (1996). The Scholarship of Engagement. Journal of Public Service and Outreach, 1(1), 11-20.

Butcher, J., Bezzina, M., \& Moran, W. (2011). Transformational partnerships: A new agenda for higher education. Innovative Higher Education, 36, 2940. doi:10.1007/s10755-010-9155-7

Cavallone, M., M., Ciasullo, V., Manna, R., \& Palumbo, R. (2020). A tale of two stakeholders: achieving excellence by merging quality expectations in Higher Education institutions. Studies in Higher Education, 1-16. doi:10.1080/03075079.2020.1739016

Cohen, C., Manion, L., \& Morrison, K. (2018). Research methods in education. London and New York: Routledge.

de la Torre, E. M., Rossi, F., \& Sagarra, M. (2018). Who Benefits from HIEs Engagement? An Analysis of priority stakeholders and activity profile of HEIs in the United Kingdom. Studies in Higher Education, 1-20. doi. 10.1080/03075079.2018.1479847

Donaldson, T., \& Preston, L. E. (1995). The Stakeholder theory of the corporation: Concepts, evidence, and implications. Academy of Management Review, 20 (1), 65-91.

Dziewanowska, K. (2017). Value types in higher education - Students' perspective. Journal of Higher Education Policy and Management, 39 (3), 235-46. doi: 10.1080/1360080X.2017.1299981

Evan, W., \& Freeman, R. E. (1988). A Stakeholder theory of the modern corporation: Kantian capitalism. In T. L. Beauchamp and N. Bowie (Eds.), Ethical theory and business (97-103). Englewood Cliffs, NJ: Prentice-Hall.

Freeman, R. E. (1984). Strategic Management: A stakeholder approach. Boston, MA: Pitman.
Garvare, R., \& Johansson, P. (2010). Management of sustainability- A stakeholder theory. Total Quality Management and Business Excellence, 21(7), 737-744.

doi:10.10.80/14783363.2010.483095

Guijt, I. (2014). Participatory Approaches. Methodological Briefs. (Impact Evaluation 5). UNICEF Office of Research, Florence.

Guijt, I., \& Gaventa, J. (1998). Participatory monitoring and evaluation: Learning from change. (IDS Policy Briefing No.12). University of Sussex, Brighton.

Jongbloed, B., Enders, J., \& Salerno, C. (2008). Higher education and its communities: Interconnections, interdependencies and a research agenda. Higher Education,56, 303-324. doi:10.1007/s10734008-9128-2

Labanauskis, R., \& Ginevičius, R. (2017). Role of stakeholders leading to development of higher education services. Engineering Management in Production and Services,9 (3), 6375. doi.org/10.1515/emj-2017-0026

Mainardes, E., Alves, H., \& Raposo, M. (2013). Identifying stakeholders in a Portuguese university: A case study. Revista de Educación, 362, 429-457. doi: 10.4438/1988-592X-RE-2012-362167

Marić, I. (2013). Stakeholder Analysis of Higher Education Institution. Interdisciplinary Description of Complex Systems, 11(2), 217-226. doi: 10.7906/indecs.11.2.4

Marshall, S. J. (2018). Internal and external stakeholders in higher education. In S. J. Marshall (Ed.), Shaping the university of the future: Using technology to catalyse change in university learning and teaching (77-102). Singapore: Springer.

Melewar, T. C., \& Akel, S. (2005). The role of corporate identity in the higher education sector. Corporate Communications: An International Journal, 10 (1), 41-57. doi:10.1108/13563280510578196 
Merrill, B., Finnegan, F., O'Neill, J., \& Revers, S. (2020). "When it comes to what employers are looking for, I don't think I'm it for a lot of them": Class and capitals in, and after, higher education. Studies in Higher Education, $45 \quad(1)$, 163-75. doi: 10.1080/03075079.2019.1570492

Mitchel, R. K., Agle, B. R., \& Wood, D. J. (1997). "Toward a Theory of Stakeholder Identification and Salience: Defining the Principle of Who and What Really Counts." Academy of Management Review. 22 (4), 853-886.

Pfeffer, J. (1981). Power in Organization. Marshfield, MA: Pitman Publishing Corp.

Rubens, A., Spigarelli, F., Cavicchi, A., \& Rinaldi, C. (2017). Universities' third mission and the entrepreneurial university and the challenges they bring to higher education institutions. Journal of Enterprising Communities: People and Places in the Global Economy, 11(3), 354-372. doi: 10.1108/JEC01-2017-0006

Schoen, A., Laredo, P., Bellon, B., \& Sanchez, P. (2007). Observatory of European University: PRIME Position Paper, version March 2007. Available at: http://www.primenoe. org/Local/prime/dir/Projects/OEU/ OEU\%20position\%20paper\%20march 2007.pdf

Strier, R. (2014). Fields of paradox: University-community partnerships. Higher Education, 68 (2), 155-165. doi.org/10.1007/s10734-013-9698-5

Suchman, M.C. (1995). Managing legitimacy: Strategic and institutional approaches. Academy of Management Review, 20 (3), 571-610.

Trencher, G., Yarmie, M., McCormick, K. B., Doll, C. N., \& Karines, S. B. (2014). Beyond the third mission: Exploring the emerging university function of co-creation for sustainability. Science and Public Policy, 41(2), 151-179. doi.org/10.1093/scipol/sct044. 